\title{
Literature and the Arts in Mathematical Education
}

\author{
Stanley J. Farlow ${ }^{1 *}$ \\ ${ }^{1}$ Professor Emeritus of Mathematics, University of Maine, U.S.A.
}

\section{ART IN MATHEMATICAL EDUCATION}

I'd like to start off the discussion about the role of art in mathematics education, or more generally about the importance of visualizing abstract concepts, with the simple equation.

$$
\frac{1}{r^{2}} \frac{\partial}{\partial r}\left(r^{2} \frac{\partial u}{\partial r}\right)+\frac{1}{r^{2} \sin \theta} \frac{\partial}{\partial \theta}\left(\sin \theta \frac{\partial u}{\partial \theta}\right)+\frac{1}{r^{2} \sin ^{2} \theta} \frac{\partial^{2} u}{\partial \phi^{2}}=0
$$

If you're not a professional mathematician, upon viewing this famous equation, you are apt to suffer heart palpitations. On the other hand, if you are a professional mathematician, you are not apt to get heart palpitations, but more apt to visualize in your mind's eye, the myriad of phenomena that the equation depicts. You see, we write equations, but we visualize their meaning.

The above equation is called Laplace's equation and as one who has derived, solved, applied, and carried out every conceivable mathematical operation on it known to humankind, I often recall a game that I played as a child when I see the equation. I'm not saying the game taught me anything about Laplace's equation, but the game's geometric underpinnings did teach me geometric and mathematical principles. I just didn't realize it at the time.

Many people are unaware that mathematics is more than numbers and long-winded equations, but rears its head in subtle ways in all sorts of childhood activities, including art, games, toys, drawings and poems. It's just not that obvious.

This special EURASIA issue on Literature and the Arts in Mathematics Education contains several insightful essays showing how teachers and practitioners of mathematics have applied art, games, and other creative tools as motivation for teaching mathematics.

\begin{abstract}
In the paper How Does Realistic Mathematics Education Improve Students' Mathematics Cognitive Achievement? by John Batlolona et al., the authors demonstrate how certain board games act as effective tools in introducing mathematical principles. In Development of Mathematical Thinking Through Integration of Ethno-mathematic Folklore Game in Math Instruction by Fouze and Amit, the authors illustrate how cultural and folkloric games can be integrated successfully in a mathematics curriculum. And finally in Art and Geometry of Plants: Experience in Mathematical Modelling Through Projects, Fabio Nelson Zapata Grajales observes how geometric patterns in nature can illustrate principles of mathematics.
\end{abstract}

\section{LITERATURE IN MATHEMATICAL EDUCATION}

I once asked the students in a calculus class to write a short story, a genre of their own choosing, which conveyed some mathematical principle they had learned over the course of the semester. The goal of the assignment wasn't to produce any literary masterpiece, but to provide the student with the opportunity to pursue an alternate mode for exploring mathematics.

Naturally, my unorthodox assignment was met with howls of protest from the class, but upon reading their stories, I was, to put it mildly, shocked. I'd never seen such wild imaginations applied to mathematics in my life. One student wrote a futuristic story related to the Fundamental Theorem of Calculus in which a character in the story discovered a novel application of the famous theorem. His idea was, of course, $100 \%$ off the charts, but the experience of embedding mathematics in literature opened the door for new ways to think about mathematics.

I have also on occasion assigned students to rewrite the definitions and problems in the textbook, paraphrasing the material in their own language and having the students read their handiwork to the class. This exercise allows the student to engage in original pedagogical research, albeit basic, in writing easy to understand yet precise mathematics, not always an easy task. 
Some of the contributions in this special issue demonstrate how storytelling and poetry can play a role in teaching mathematics.

\begin{abstract}
The poem in Learning Mathematics: Like Proposing Love to a Girl by S. Chirume is an allegory depicting mathematics through African culture. The poem illustrates how both poetry and mathematics are beautiful and precise. In her paper Why Literacy Should be Included in an Effective Math Curriculum, Adrienne Sturgeon shares some innovative lesson plans she has used in the past to teach 5-7 year-olds about numbers and their arithmetic.
\end{abstract}

Now that the subject of literature in mathematics has been broached, is the reader aware of how the algebraic symbol $x$ came about? You probably learned its history at some time in the past, but forgot. However, if you had learned the history of $x$ in the guise of a captivating story, you would still remember it. We now wish to check this theory by offering the reader a brief narrative account of the history of that famous symbol that has long caused consternation to the beginning student of algebra.

\title{
THE STORY OF HOW MATHEMATICIANS LEARNED TO LOVE $x$
}

When someone asks me what I do for a living, I tell them I'm trying to find $x$. Sometimes I even succeed, as when someone asks me to find the $x$ in the equation

$$
x-1=0
$$

Another time in a beginning geometry class after mastering the Pythagorean Theorem, I solved the problem in Figure 1 by finding $x$.

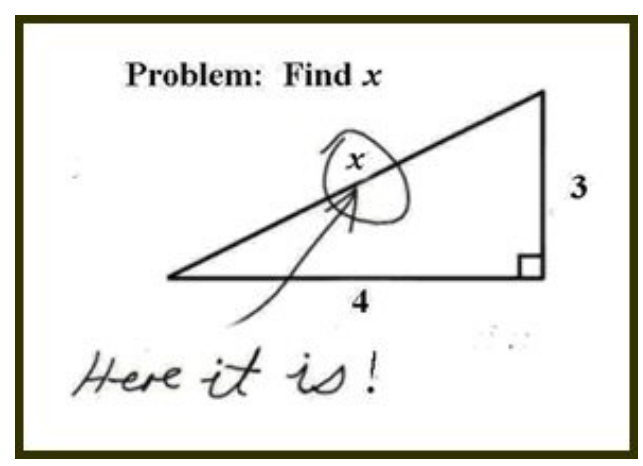

Figure 1. Finding $x$

But mathematicians are not the only people fascinated with the letter $x$. The 24th letter of the alphabet has been used for everything from "marking the spot" to warning us about "dirty movies." But the real mystery is, why do mathematicians use $x$ ? Why aren't we ever asked to find $p$ in the equation

$$
p-1=0
$$

or warn us about $p$-rated movies?

One theory is because the Spanish can't say "sh." A thousand years ago the root of mathematical learning was centered in the Islamic world, where the first systematic study of algebra was starting to percolate. When Arab mathematicians solved an equation for a certain value, they referred to the certain value as "something," which in Arabic is written as shown in Figure 2 and pronounced "sh."

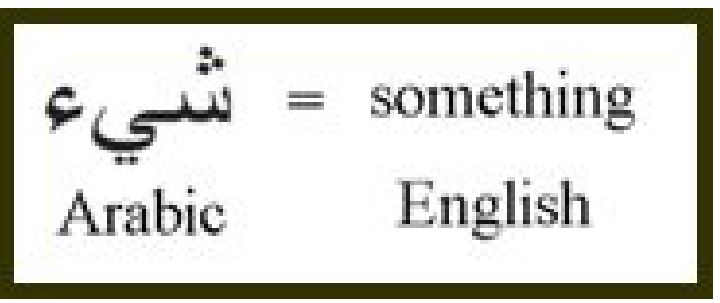

Figure 2. Arabic pronounced "sh"

When Arab mathematical texts arrived in Spain at the beginning of the European Renaissance, scholars translated these works into Spanish. The problem they faced was that the Spanish language does not contain a sound for "sh" so the translators went with the "ck" sound, which in Greek is closest to the letter chi, written as $\chi$. 
But European writers of math books preferred Latin letters to Greek letters and so the Greek $\chi$ morphed into the Latin $x$.

And like they say, the rest is history.

$$
\text { - - ada } \Xi \Xi \Xi a d a--
$$

The theory of how math discovered $x$ has some similarities to how Christmas is sometimes expressed as Xmas - religious scholars used the Greek letter chi as shorthand for Christ.

Nowadays, it is fashionable to steal the mathematical $x$, which is understood to stand for the "unknown" or "mystery." There are X-rays, which were invented in the 1890s, and at the time were of unknown origin. Then there were the Black Muslims, who adopted new names as replacements for their slave names, the most famous being Malcolm X. And don't forget about the Generation Xers, who are essentially Baby Boomers who lie about their age.

The Los Alamos National Laboratory even has a super-secret division, called the X Division, where some of our nation's top eggheads are responsible for the safety and reliability of the nation's nuclear deterrent. One wonders about the intelligence of using $X$ to designate its most secret area in the country in as much as any spy worth his secret decoder ring who managed to sneak into the place would head right for the $\mathrm{X}$-files and not waste any time on the $A$-files.

$$
\text { - - ada } \Xi \Xi \Xi a d a--
$$

But there are other theories about how mathematics fell in love with the $x$. The problem with the above theory of

$$
\text { Arab } \rightarrow \text { Spanish } \rightarrow \text { English }
$$

is firstly, there is no documented evidence to support it, and secondly, medieval scholars who translated these works cared little about the phonetics of words but on their meaning.

For another and more documented version of the story of $x$, we turn to the French philosopher and mathematician Renè Decartes, who used $x$ in his 1637 seminal work La Géométrie. It is uncertain whether Descartes originated the idea for using $x$ as a practice for representing an unknown quantity or borrowed it from someone else. Nevertheless, as far as documented evidence goes, he seems to be the creator, if not the person who popularized its use, as noted by the math historian Florian Cajori in his book A Theory of Mathematical Notations.

In La Géométrie, Decartes solidified the mathematical notation we use today with $a, b$ and $c$ designating known quantities and $x, y$ and $z$ designating unknown quantities.

(the end)

\section{http://www.ejmste.com}

